\title{
Commentary: Lung failure has been waiting for this
}

\author{
Pedro Reck dos Santos, MD, MSc, and \\ Jonathan D'Cunha, MD, PhD
}

Implantable portable devices that can offer alternatives to the current mechanical circulatory support (MCS) platforms are essential because they can theoretically allow the patient to transition from an intensive care unit to the ward or even the outpatient setting. The field of heart failure was transformed when this possibility was realized in the 1990s with the development of the left ventricular assist device (LVAD). Griffith and colleagues ${ }^{1}$ discuss an exciting strategy that can, as pointed out by the authors, "permit [extracorporeal membrane oxygenation] ECMO systems to leave at the bedside, encourage exercise, and be suitable for use out-of-hospital."

These are important and achievable technological advancements that we have all been waiting for since the LVAD. Patient who are dependent on MCS are extremely sick, and, as discussed by the authors, only recently VAD technology moved toward good survival and quality of life for patients. ${ }^{1}$ This transition has been challenging and lengthy. While advancements in technology allowed better perfusion circuits, tubing, cannulas, and so on, a critical part of this equation continues to be selecting which patient will benefit the most.

Patients who have acute respiratory distress syndrome and require MCS are in critical condition, facing many challenges simultaneously. Overcoming a nutritional equation that is not easy to balance, maintaining mobility, avoiding infections, having family support, and maintaining a positive psychological attitude are only a few issues that

From the Department of Cardiothoracic Surgery, Mayo Clinic Arizona, Phoenix, Ariz.

Disclosures: The authors reported no conflicts of interest.

The Journal policy requires editors and reviewers to disclose conflicts of interest and to decline handling or reviewing manuscripts for which they may have a conflict of interest. The editors and reviewers of this article have no conflicts of interest.

Received for publication Oct 31, 2021; revisions received Oct 31, 2021; accepted for publication Nov 1, 2021; available ahead of print Nov 13, 2021.

Address for reprints: Jonathan D'Cunha, MD, PhD, Department of Cardiothoracic Surgery, Mayo Clinic Arizona, 5777 E Mayo Blvd, Phoenix, AZ 85054 (E-mail: DCunha.Jonathan@mayo.edu).

JTCVS Open 2021;8:114-5

2666-2736

Copyright (C) 2021 The Author(s). Published by Elsevier Inc. on behalf of The American Association for Thoracic Surgery. This is an open access article under the CC BY-NC-ND license (http://creativecommons.org/licenses/by-nc-nd/4.0/).

https://doi.org/10.1016/j.xjon.2021.11.001

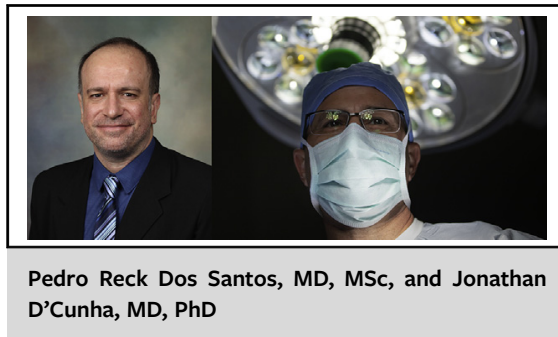

CENTRAL MESSAGE

Technological advancements will be crucial for developing reliable

long-term portable mechanical pulmonary support. Herein we review recent such

advancements.

need to be addressed by a multidisciplinary approach with committed teams. ${ }^{2}$

During the coronavirus disease 2019 (COVID-19) pandemic, MCS has played a significant role in the management of critical patients. While some patients with endstage lung disease benefited from lung transplantation, ${ }^{3}$ it is interesting to note that others were initially referred for experienced transplant centers but ended up not being candidates for this therapy because their lung function remained adequate while on ECMO support, eventually leading to recovery. Lungs needed time to allow recovery, and we are learning every day about this predictability. We remain concerned about the long-term outcome of these patients.

The development and implementation of this technology for patients with lung failure who are candidates will be transformative to the field like it has been for patients with heart failure. For example, how do we manage a patient dependent on ECMO who is not a transplant candidate? COVID-19 taught us that we need to be ready. By achieving safe, long-term, and portable pulmonary support, opportunities also to improve patient's frailty, quality of life can dramatically change an outcome. Those patients who were not candidates for lung transplantation may be supported and rehabilitated to a position of consideration.

Additionally, as therapies for lung injury will undoubtedly be developed, portable and durable MCS devices will also be critical to support these patients. Other technologies are also being investigated. ${ }^{4}$ However, the transition is 
not easy, and we congratulate the authors on their research and efforts. We are enthusiastic about the approach of Griffith and colleagues, where the use of oxygen concentration comes from the ambient air. Not only is this group and this work visionary, the simplicity of their device is also relevant - the simpler, the better-and also suits venovenous and venoarterial modes. Visual inspection for thrombosis is also crucial. Importantly, the authors pointed out surface modifications of the membrane oxygenator and future implications.

What is next? Technology will undoubtedly improve over time, and we are confident that portable mechanical pulmonary support will be a key part of our lung failure future. We have been waiting for this.

\section{References}

1. Griffith BP, Wu ZJ, Zhang J. Pasta for all: abiomed Breethe extracorporeal membrane oxygenation system. J Thorac Cardiovasc Surg Open. 2021;8:108-13.

2. Meyer NJ, Gattinoni L, Calfee CS. Acute respiratory distress syndrome. Lancet 2021;398:622-37

3. Bharat A, Machuca TN, Querrey M, Kurihara C, Garza-Castillon R, Kim S, et al Early outcomes after lung transplantation for severe COVID-19: a series of the firs consecutive cases from four countries. Lancet Respir Med. 2021;9:487-97.

4. Orizondo R, Omecinski KS, May AC, Dhamotharan V, Frankowski BJ, Burgreen GW, et al. Month-long respiratory support by a wearable pumping artificial lung in an ovine model. Transplantation. 2021;105:999-1007. 